\title{
Nano-Detoxification of Organophosphate Agents by PAMAM Derivatives
}

\author{
Esteban F. Durán-Lara, ${ }^{a, b}$ Fabian Ávila-Salas, ${ }^{a, b}$ Sebastian Galaz, ${ }^{b}$ Amalraj John, ${ }^{a, b}$ \\ Adolfo Maricán, ${ }^{b}$ Margarita Gutiérrez, ${ }^{c}$ Fabiane M. Nachtigall, ${ }^{b}$ \\ Fernando D. Gonzalez-Nilo ${ }^{d}$ and Leonardo S. Santos $*, a, b$ \\ ${ }^{a}$ Laboratory of Asymmetric Synthesis, Institute of Chemistry and Natural Resources, \\ University of Talca, 747 Talca, Maule, Chile \\ ${ }^{b}$ Nanobiotechnology Division, Fraunhofer Chile Research Foundation, \\ Center for Systems Biotechnology (FCR-CSB), 747 Talca, Maule, Chile \\ ${ }^{c}$ Organic Synthesis Laboratory, Institute of Chemistry of Natural Resources, \\ University of Talca, 747 Talca, Maule, Chile \\ ${ }^{d}$ Universidad Andres Bello, Center for Bioinformatics and Integrative Biology, \\ Facultad de Ciencias Biológicas, Av. República 239, 8370146 Santiago, Chile
}

Vol. 26, No. 3, 580-591, 2015.

http://dx.doi.org/10.5935/0103-5053.20150013

\section{Page 590, Acknowlegements section:}

This work was supported by a grant from E. Durán and L. S. Santos FONDECYT (Postdoctoral Grant No. 3120178) and Innova Chile CORFO Code FCR-CSB 09CEII-6991. The authors acknowledge support from Proyecto Anillo Científico ACT1107. Fabian Avila thanks for doctoral scholarship to CONICYT-PCHA/Doctorado Nacional 2013-21130308. Fondecyt 11130086 (F.M.N.) and PIEI (Química y Bio-orgánica en Productos Naturales) from UTalca is also acknowledged.

\section{Will change to:}

This work was supported by a grant from E. Durán and L. S. Santos FONDECYT (1140642 and Postdoctoral Grant No. 3120178) and Innova Chile CORFO Code FCR-CSB 09CEII-6991. The authors acknowledge support from Proyecto Anillo Cientifico ACT1107. Fabian Avila thanks for doctoral scholarship to CONICYT-PCHA/Doctorado Nacional 2013-21130308. Fondecyt 11130087 (A.J.), 11130086 (F.M.N.) and PIEI (Química y Bio-orgánica en Productos Naturales) from UTalca are also acknowledged. 